\title{
Erken çocukluk dönemi öğretmenlerinin çokkültürlülüğe dair bakı̧̧ açıları ve uygulamaları üzerine bir inceleme*
}

\author{
An investigation of early childhood education teachers' perspectives and \\ practices of multiculturalism
}

\author{
Gözdenur IŞIKCI BAŞKAYA ${ }^{1}$, Fatma ALISININANOĞLU² ${ }^{2}$, Hasibe Özlen DEMIRCAN \\ Fatma TAHTA ${ }^{4}$
}

\section{Makale Geçmişi \\ Geliş : 27 Ocak 2020 \\ Düzeltme : 26 Mays 2020 \\ Kabul : 16 Haziran 2020}

\section{Makale Türü}

Araştırma Makalesi

\section{Article History \\ Received : 27 January 2020 \\ Revised : 26 May 2020 \\ Accepted : 16 June 2020}

Article Type

Research Article
Öz: Eğitim alanında çokkültürlülük her ailenin özgünlüğü ve onlarla çalışmanın getirdiği etkiler ile tüm çocuklar için eşit eğitim firsatları oluşturma; farklılıkları takdir etme olarak tanımlanmaktadır. Çokkültürlülük aynı zamanda toplumdaki temel eşitsizlikleri değiştirmek için çocukları girişimde bulunmaya teşvik eden bir araç olarak da değerlendirilmektedir. Bu çalışma, erken çocukluk dönemi öğretmenlerinin eğitimde çokkültürlülük bakış açılarını, sınıfta uyguladıkları çok kültürlü etkinlikleri ve çok kültürlü ailelerle yaptıkları aile katılım uygulamalarını incelemeyi amaçlamaktadır. Bu amaçla, İstanbul'da üç farklı anaokulunda 7 öğretmenden veri toplanmıştır. Bulgular, "Çokkültürlülük Tanımları”, "Çokkültürlü Aile Anlayışları”, "İletişim Yöntemleri”, “Çokkültürlü Etkinlikler” ve "Aile Katılım Tanımları" olarak tanımlanan 5 ana tema altında gruplanmıştır. Bulgular geniş bir perspektiften değerlendirildiğinde; erken çocukluk eğitimi öğretmenlerinin çok kültürlü anlatılarında benzer ve farklı yönleri olduğu söylenebilir. Ayrıca, farklı çokkültürlülük bakış açıları çok-kültürlü faaliyetlerin uygulanmasını desteklemektedir.

Anahtar Kelimeler: Çokkültürlülük, Aile katılımı, Erken çocukluk eğitimi, Çokkültürlü aile

Abstract: Multiculturalism in terms of education is defined as creating equal educational opportunities for all children and appreciating differences with the specificity of each family and the effects of working with them. This study aims to examine the multicultural perspectives of early childhood teachers in education, the multicultural activities they practice in the classroom and their family involvement practices with multicultural families. Data were collected from 7 teachers in three different preschools in Istanbul. Findings revealed 5 main titles defined as "Definitions of Multiculturalism", "Their Understanding of Multicultural Family", "Communication Methods", "Multicultural Activities" and "Definitions of Parent Involvement". When the findings of the study were evaluated from a broad perspective; it can be stated that early childhood education teachers have both similar and different aspects at the same time, in their multicultural narratives. Also, their different perceptions of multiculturalism support the implementation of multicultural activities.

Keywords: Multiculturalism, Parent involvement, Early childhood education, Multicultural family 


\section{SUMMARY}

\section{Introduction}

Multiculturalism is considered as seeking equality by removing prejudice between racial and ethnic groups (Moawad and Shoura, 2017). When multiculturalism is considered from cultural and social perspective, it is thought to be a cultural movement that emphasizes the diversity of the country's culture and society (Mendible, 1999). For this reason, multiculturalism is one of the issues that need to be addressed in a rapidly changing and globalizing world because it emerges in various fields of society such as education and health. In terms of education, multiculturalism means that the school environment reflects different cultures and provides equal learning opportunities for all children (Banks, 2002). Accordingly, the responsibility of establishing the intercultural bridge in classroom practices falls to teachers to a large extent (Kurtuluş, 2018). It is important for early childhood teachers to include multiculturalism in both class activities and parent involvement practices in terms of teaching children how to respect and understand individual differences and to have cultural competence in this direction. At this point, Derman-Sparks and Edward (2010) emphasize that all families should have access to resources fairly in order for the class environment to nurture multiculturalism. Studies in national and international literature generally focus on the attitudes and beliefs of early childhood teachers and prospective teachers on multiculturalism (Berthelsen, 2011; Hong, 2017). In this context, the purposes of this study are:

a) To learn about the perspectives of early childhood teachers about multiculturalism

b) To learn about the multicultural activities that early childhood teachers use in the classroom.

c) To learn about the parent involvement studies of early childhood teachers with multicultural families.

\section{Method}

In this research, the phenomenological research method, one of the qualitative research patterns, was used. The sample of this study consists of seven early childhood teachers working in 3 different preschool education institutions in Istanbul. "Demographic Information Form" and "Interview Form" were used as data collection tools. Preschool education institutions were visited and face-to-face interviews were held with teachers. The collected data were analyzed by content analysis technique and five main themes were determined: "Definitions of Multiculturalism", "Their Understanding of Multicultural Family", "Communication Methods", "Multicultural Activities" and "Definitions of Parent Involvement".

\section{Results}

When the definitions of early childhood teachers about multiculturalism were examined, it was determined that their definitions were shaped around concepts such as race, religion, language, and socioeconomic status. It was determined that some early childhood teachers received informal interpreter support and preferred third channels in communication with families. When participants were asked to define parent involvement, it was seen that they classified it as home-based and school-based. Some early childhood 
teachers described the multicultural family as a family with different religions, languages, or races while other teachers defined the multicultural family as a family that reads and travels a lot. It was found that some of the participants emphasized the differences between cities and countries in their classroom activities. It was found that other early childhood teachers dealt with the issue of multiculturalism in classroom activities which were held on certain days and weeks. When the parent involvement activities implemented by the participants were examined, it was concluded that they organized city/country promotion activities with the families.

\section{Conclusion and Discussion}

As the definitions of multiculturalism of the participants were examined, it was found that some teachers addressed multiculturalism within the framework of race, language and socioeconomic status. However, family structure, sexual orientation and age are accepted as the main factors leading to multiculturalism (Berger, 2004; Polat \& K1liç, 2013). This situation can be interpreted in the sense that teachers have limited knowledge about the elements that constitute multiculturalism. In parallel with the findings of the current study, a study by Berthelsen and Karuppiah (2011) found that teachers' multicultural understanding was limited. Although other teachers participating in the current study did not have a definition of multiculturalism, it might be considered hopeful that they had been implementing multicultural activities in their classroom practice. The fact that teachers had knowledge about multiculturalism played an important role in communication and interaction with the families.

Close relationships with families in early childhood are based on mutual trust and respect. Considering Bronfenbrenner's Ecological Systems Theory, the open communication of the teacher and the family is an important factor that strengthens the relationship between microsystems and thus the mesosystem. When working with families from different backgrounds, establishing this relationship can be difficult for teachers (Eberly, Joshi \& Konzal, 2017). In addition, language differences create a barrier for the family involvement process (Hughes and MacNaughton, 2000). There are similar studies in the literature stating that language sets a barrier when working with multicultural families (Hughes \& MacNaughton, 2000; Rios \& Wynn, 2017). Considering how effective the school-home communication is at school (Vassallo, 2018), the fact that the communication process with multicultural families is bilateral and open plays a critical role.

Teachers were asked to define parent involvement and the findings showed that teachers divided parent involvement process as home-based and school-based. Although this situation coincides with the definitions of family involvement in the relevant literature (Demircan, 2018; Hornby, 2011), the preferred methods of communication with multicultural families are not sufficient to establish cooperation. The active role of teachers in parent involvement should be evaluated positively in terms of education programs and child development. Because there are studies showing that the teachers do not have enough information about parent involvement and that the negative perceptions of the teacher are a barrier in the parent involvement process (Johnson, 2011). 
Considering the multicultural activities applied by the teachers, it was found that the participants performed practices regarding multiculturalism both in the classroom and in the parent involvement process. Especially when examining in-class activities, it was revealed that some teachers focused on multicultural families' volunteerism activities describing their culture and the city/countries they came from. Research reveals that multicultural families were less involved in the school process (Artiles, Kozleski, Trent, \& Ortiz, 2010; Fishman \& Nickerson, 2015). In this context, teachers' planning of parent involvement activities for multicultural families should be considered as a situation that encourages and increases the school participation process of multicultural families. When the findings of the study are evaluated, it can be stated that preschool teachers working in different institutions have both similar and different aspects in the definition of multiculturalism. 


\section{GİRİŞ}

Bireysel farklılıklar ve benzerlikler açısından bireylerin dil, din, 1rk, cinsel yönelim, yaş ve aile yapıları çokkültürlülük çerçevesinde ele alınmaktadır (Polat ve Kılıç, 2013). Kültürel ve sosyal açıdan ele alındığında, çokkültürlülüğün toplumunun çeşitliğine vurgu yapan kültürel bir hareket olduğu düşünülmektedir (Mendible, 1999). Politik açıdan düşünüldüğünde ise çokkültürlülügün toplumda yer alan kültürel ve dini çeşitliliğe doğru yoldan cevap veren düşünce topluluğu olduğu kabul edilmektedir (Rattansi, 2011). Bir başka anlayışa göre ise çokkültürlülük ırk ve etnik gruplar arasındaki önyargıyı kaldırarak eşitlik aramak olarak değerlendirilmektedir (Moawad ve Shoura, 2017). İlgili alanyazın incelendiğinde çokkültürlülüğe dair ortak bir tanımın olmadığ1 görülmektedir çünkü insanlar arasındaki bireysel farklılıkların ve benzerliklerin temsili olarak ele alınan çokkültürlülük sosyal ve kültürel açıdan birçok boyutu içermekte olan bir kavramdır (Tiedt ve Tiedt, 2005). Yine de çokkültürlülüğün toplumda yer alan farklllıklara odaklanan ve farklı kültürlerin bir arada var oluşuna sayg1 duymayı ele alan bir kavram olduğu düşünülebilir. Bu sebeple çokkültürlülük, toplumsal açıdan hızla değişen ve küreselleşen dünyada ele alınması gereken öncelikli konulardan biri olarak düşünülmelidir.

Günümüzde göç, teknolojik ve ekonomik değişimler gibi sebeplerle hızla değişen sosyo-demografik ve sosyo-kültürel yapı, jeopolitik konumu dolayısı ile Türkiye’yi çokkültürlü bir ülke konumuna getirmektedir (Aydın, 2012). Türkiye Göç İdaresi Genel Müdürlüğ̈̈nün (2019) verilerine göre, 2019 yllında 1.107.934 yabancının Türkiye'de oturma izni bulunmaktadır. Göçmenler yoğun olarak Azerbaycan, Rusya, Ukrayna, Suriye ve Çin gibi çeşitli ülkelerden göç etmiştir. Bu durum Türkiye'nin özellikle dil, din ve etnik köken bakımından çokkültürlü bir toplum olmasına yol açmaktadır (Polat ve Kılıç, 2013). Öte yandan Berger (2004)'a göre; dil, din ve etnik kökene ek olarak bireylerin sosyo-ekonomik durumları ve aile yapıları da çokkültürlülüğe yol açmaktadır. $\mathrm{Bu}$ bağlamda çokkültürlülük kavramı, eğitim ve sağlık gibi toplumun çeşitli alanlarında karşılaşılan bir kavramdır. Özellikle çokkültürlülüğü hem etkileyen hem de bundan etkilenen alanlardan biri, okul bağlamının çok dilli, çok ırklı ve çok kültürlü çeşitliliği nedeniyle eğitimdir (Banks, 2002).

Eğitim açısından çokkültürlülük, okul ortamının değişik kültürleri yansıtması ve tüm çocuklar için eşit öğrenme firsatları sağlamayı ifade etmektedir (Banks, 2002). Fakat çokkültürlü aile yapısından gelen çocuklar ve aileleri dil problemleri, kültürel yapıya uyumsuzluk ve uyarımlara yabancı olma gibi birçok problemle karşılaşabilmektedir (Keat, Strickland \& Marinak, 2009; Schölmerich vd., 2008). Özellikle dil çocukların okul yaşantısına yön veren temel faktör konumundadır (Yanık-Özger ve Akansel, 2019). Bu konuda yapılan çalışmalar aile desteği ve öğretmen yaklaşımı gibi unsurların 
çocukların dil problemlerinin üstesinden gelmede rol oynadığını ortaya koymaktadır (Yanık-Özger ve Akansel, 2019). Bu noktada aile katılımının sağlanması önemli bir unsur olmasına rağmen çokkültürlü aileler, aile katılım sürecinde sınırlı gelir, ulaşım ve çalışma saatleri gibi bir çok engelle karşılaştıklarını bildirirken (Lahaie, 2008; Lareau, 1987; Turney ve Kao, 2009) çokkültürlü aileler ile çalışmakta olan öğretmenler ise dil, kültür ve gelenek farklllıkları sebebiyle çokkültürlü aileleri okul sürecine dahil etmede zorlukla karşılaştıklarını ifade etmişlerdir (Barnett, Yarosz, Jung, \& Blanco, 2007; Lin, 2005). Yapılan diğer çalışmalar sosyoekonomik durum, dil ve kültürel faktörlerin ebeveynler ve öğretmenler arasındaki ilişkinin düzeyini ve doğasını etkilediğini ortaya koymuştur (Keyes, 2002; Ladky ve Stagg-Peterson, 2008; Vellymalay, 2012). Diğer yandan çokkültürlülük aynı zamanda her ailenin özgünlüğü ve onlarla çalışmanın getirdiği etkiler ile tüm çocuklar için eşit eğitim firsatları oluşturma ve farklılıkları takdir etmeyi içermektedir (Lynch ve Hanson, 1998). Bu sebeple çokkültürlülük kavramı aileleri de içine alan geniş bir kavram olarak düşünülmeli ve aile katıllım etkinlikleri aracılı̆̆ı ile çokkültürlü aileler okul sürecine dâhil edilmelidir.

Aile katılımı temel olarak ebeveynlerin çocuklarının eğitim süreçlerine ve deneyimlerine hem ev temelli hem de okul temelli olarak dahil olmasi/edilmesi olarak tanımlanmaktadır (Hornby, 2011). Başarılı bir aile katılımı ise okul ile aile arasında kurulan güçlü bir ortaklık olarak değerlendirilmektedir (Demircan, 2018). Bu tanımlardan yola çıkarak aile katılım sürecinin yalnızca ev ortamında değil, aynı zamanda okul ortamında hem diğer ebeveynlerle hem de öğretmenle etkileşim kurarak gerçekleştiği söylenebilir. Çokkültürlülüğün tüm çocuklar ve aileleri için adil eğitim firsatı oluşturmayı içerdiği düşünüldüğünde, erken çocukluk öğretmenlerinin aile katılım etkinlikleri aracılığı ile çokkültürlü aileler ve okul arasında köprü kurması beklenmektedir. Bu sayede çocukların çokkültürlülüğü aile katılımı bağlamında öğrenmesi de sağlanabilir. Swick, Boutte ve Scoy (1994) bu noktada öğretmenlere üç strateji önermektedir. İlk olarak erken çocukluk dönemi öğretmenlerinin ebeveyn eğitimi ve desteği sağlayarak çokkültürlülüğü tartışabilecekleri bir ortam sağlaması gerekmektedir. Ek olarak öğretmenlerin okul-aile müfredat faaliyetleri kapsamında çokkültürlülük ile ilişkili alan gezileri, çokkültürlü materyal tasarımları, çokkültürlülüğe ilişkin sınıf içi etkinlikler düzenlemeleri önerilmektedir. Bu etkinlikler sırasında çocukların ebeveynlerinin bakış açısından çokkültürlülüğü öğrenmeleri önem taşımaktadır çünkü bu alanda yapılan çalısmalar ebeveynlerin sahip oldukları tutumların ve aile katılım sürecine katılımlarının, çocuklar için olumlu ırksal ve kültürel bakış açısını modellemek için doğal fırsatlar sunduğunu ortaya koymaktadır (Swick vd., 1994). Bir diğer strateji ise ebeveyn ve öğretmen arasında güçlü bir ortaklık kurarak çocukları çokkültürlü bir topluma hazırlamaktadır (Swick vd., 1994). Bu noktada Derman-Sparks ve Edward (2010), sınıf ortamının çokkültürlülüğü beslemesi için tüm ailelerin kaynaklara adil bir şekilde ulaşması gerektiğini vurgulamaktadır. Bunu sağlamanın yollarından biri olarak çocuğun ailesinin 
fark edilmesi gösterilmiştir (York, 2016). Bu sebeple çokkültürlü eğitim uygulamalarında ailelerin de sürece dâhil edilmesi kritik bir rol oynamaktadır. Bu bağlamda erken çocukluk dönemi öğretmenlerine düşen sorumluluklardan biri okul ve aile arasında işbirliği kurarak kapsayıcı aile katılım süreci hazırlamak olmalıdır.

Alanyazın incelendiğinde erken çocukluk dönemi öğretmenlerinin çokkültürlülüğe dair tutumlarını ve uygulamalarını inceleyen çeşitli çalısmalara rastlanmaktadır (Berthelsen \& Karuppiah, 2011; Özözen-Danacı ve diğerleri, 2016; Taştekin ve diğerleri, 2015). Düzce ilinde yapılan bir çalışmada, öğretmenlerin çokkültürlü eğitime yönelik tutumlarının mezun oldukları üniversitenin yer aldığ1 şehir, kıdem, görev yaptıkları okulun bulunduğu bölge ve boş zaman etkinliklerine göre değiştiği tespit edilmiştir (Özözen - Danacı ve diğerleri, 2016). Örneğin, merkezde görev yapan erken çocukluk dönemi öğretmenlerinin çokkültürlü eğitime dair tutumlarının köyde görev yapan öğretmenlere göre daha olumlu olduğu bulunmuştur (Özözen - Danacı ve diğerleri, 2016). Taştekin ve diğerleri (2016) tarafindan yapılan bir çalışmada ise erken çocukluk dönemi öğretmenlerinin çokkültürlü eğitime ilişkin algıları araştırılmış ve öğretmenlerin olumlu tutuma sahip olmalarına rağmen uygulama konusunda daha yeterli olmaları gerektiği tespit edilmiştir. Türkiye'den bağımsız olarak uluslararası alanyazında da erken çocukluk dönemi öğretmenlerinin çokkültürlülük uygulamaları konusunda zorluklar yaşadığını gösteren çalışmalar mevcuttur (Berthelsen ve Karuppiah, 2011). Singapur'da yapılan bir çalşmada erken çocukluk dönemi öğretmenleri çocuklarda hoşgörü ve anlayış gelişimi için anaokullarında çokkültürlü eğitimin olması gerektiğini savunurken uygulama konusunda zorlandıklarını ifade etmişlerdir (Berthelsen ve Karuppiah, 2011). Bu bağlamda özellikle bilgi eksikliği, destek mekanizmasının olmaması ve zaman problemleri erken çocukluk dönemi öğretmenlerinin karşılaştıkları zorluklar olarak belirlenmiştir (Hong, 2017). Sınıf içi uygulamalara ek olarak erken çocukluk dönemi öğretmenleri çokkültürlü aile çalışmaları yapma konusunda da desteğe ihtiyaç duyabilmektedir.

Erken çocukluk dönemi öğretmenlerinin çokkültürlü aileler ile etkileşim kurmasının ve erken çocukluk eğitiminde çokkültürlülüğg̈ ele almasının önemli bazı sebepleri bulunmaktadır. Öncelikle Vittrup'a (2016) göre, çocuklar yedi yaşından önce etnik köken ve ırk hakkında bazı önyargılar oluşturabilmektedir. Bu sebeple sınıfın çokkültürlü yapısından bağımsız olarak, farklılıklara duyarlı bir sınıf ortamı ve müfredat hazırlamak, çocukların kültürel önyargılarını önlemek için başlıca hedef olarak ele alınmalıdır. Bu noktada öğretmenlerin çokkültürlülük kavramını müfredatları ile bütünleştirmesine erken yıllarda başlayabilir. İkinci olarak çocukların sosyal ve duygusal gelişimleri düşünüldüğünde, kültürel duyarllık ve anlayışın gelişmesi için en uygun ortamın erken çocukluk dönemi olduğu düşünülmektedir çünkü çocuklar okul çağından önce kendi kültürlerine dair kültürel 
anlayışa sahip olmaya başlamaktadır (Lynch ve Hanson, 1998). Son olarak, erken çocukluk dönemi öğretmenlerinin hem sınıf etkinliklerinde hem de aile katılımı çalışmalarında çokkültürlülük konusuna yer vermesi çocukların farklılıklara karşı saygı duyması, bireysel farklılıkları anlaması ve bu doğrultuda kültürel yetkinliğe sahip olması açısından önemlidir. Bu doğrultuda sınıf içi uygulamalarında kültürlerarası köprüyü kurma sorumluluğu büyük oranda öğretmenlere düşmektedir (Kurtuluş, 2018).

Bu bağlamda bu durum çalışmasının amacı, İstanbul'da üç farklı okul öncesi eğitim kurumunda görev yapmakta olan erken çocukluk dönemi öğretmenlerinin çok kültürlülük anlayışlarını incelemektir. Bu doğrultuda araştırmanın 3 alt amacı bulunmaktadır.

a) Erken çocukluk dönemi öğretmenlerinin çokkültürlülüğe dair bakış açları hakkında bilgi edinmek.

b) Erken çocukluk dönemi öğretmenlerinin sınıfta uyguladıkları çokkültürlülük etkinlikleri hakkında bilgi edinmek.

c) Erken çocukluk dönemi öğretmenlerinin çokkültürlü aileler ile yaptıkları aile katılım çalışmaları hakkında bilgi edinmek.

\section{YÖNTEM}

$\mathrm{Bu}$ araştırmada, nitel araştırma desenlerinden biri olan fenomenolojik araştırma yöntemi kullanılmıştır. Fenomonolojik araştırma, katılımcılar tarafından tanımlanmış bir fenomenle ilgili bireylerin sahip oldukları deneyimlerin betimlendiği bir nitel araştırma yöntemidir (Creswell, 2013).

\section{Katılımcilar}

Bu çalışmanın örneklemini, İstanbul'da 3 farklı okul öncesi eğitim kurumunda çalışmakta olan yedi erken çocukluk dönemi öğretmeni oluşturmaktadır. Katılımcılar, uygun örnekleme yöntemiyle çalışmaya dahil edilmiştir. Veriler 2018 - 2019 eğitim - öğretim yılında toplanmıştır.

Katılımcıların yaş ortalaması 24.5 olarak bulunmuştur. Deneyim yılı ile ilgili bilgi ise Tablo 1'de sunulmaktadir. 
Tablo 1. Katılımciların deneyim yılı dağılımları

\begin{tabular}{ll}
\hline Ögretmen & Deneyim yll1 \\
\hline$\ddot{O} 1$ & 2 \\
Ö2 & 1 \\
O33 & 3 \\
O44 & 3 \\
O5 & 2 \\
O6 & 4 \\
O77 & 4 \\
\hline
\end{tabular}

Çalışmaya katılan yedi öğretmenden altısı (\%85) Çocuk Gelişimi bölümünden mezundur. Bir öğretmen ise Sosyal Hizmetler bölümü mezunu olarak çalışmaktadır. Katılımcılar farklı yaş gruplarında öğretmenlik yapmakta ve sınıflarında ise farklı kültürlerden gelen çocuklar bulunmaktadir.

Tablo 2. Çocukların yaş seviyesi ve farklı kültürden gelen çocuk sayısı

\begin{tabular}{ccc}
\hline Öğretmen & Yaş seviyesi & Farkl1 kültürden gelen çocuk sayısı \\
\hline Ö1 & 4-5 yaş & 2 \\
Ö2 & 6 yaş & 2 \\
Ö3 & 4-5 yaş & 1 \\
Ö4 & 4-5 yaş & 3 \\
Ö5 & 6 yaş & 4 \\
Ö6 & 6 yaş & 1 \\
Ö7 & 4-5 yaş & 2 \\
\hline
\end{tabular}

\section{Veri Toplama Araçları ve Veri Toplama Süreci}

Çalışma için veri toplama süreci başlamadan önce, insan Araştırmaları Etik Kurulu’na başvurularak çalışmanın öğretmenler üzerinde uygulanabilmesi için gerekli izinler alınmıştır. Etik kurul izninin ardından İl Milli Eğitim Müdürlüğü’ne başvurularak çalışmanın okul öncesi eğitim kurumlarında uygulanabilmesi için izinler alınmıştır. Veri toplama aracı olarak araştırmacılar tarafından oluşturulan "Demografik Bilgi Formu” ve "Görüşme Formu” kullanılmıştır. Demografik Bilgi Formu'nda katılımcıların deneyim yılı, mezun oldukları bölüm ve sınıfın yaş grubu gibi soruları cevaplamaları beklenmiştir. Katılımcıların çok kültürlülük uygulamalarını irdeleyecek olan form “yarı yapılandırılmış görüşme formu” olarak tasarlanmıştır. Öncelikli olarak ilgili alanyazın taranarak sorular belirlenmiş daha sonra uzman görüşü alarak son hali oluşturulmuştur. Öğretmenlerin çokkültürlülük tanımları, sınıf etkinliklerinde ve sınıfın fiziksel düzenlemesinde çokkültürlülüğe yer verip vermedikleri, çokkültürlü aile tanımları ve çokkültürlü ailelerle yaptıkları aile katılım etkinlikleri irdelenmiştir. Okul öncesi eğitim kurumları ziyaret edilerek öğretmenlerle yüz yüze görüşmeler yapılmıştır. Yapılan görüşmelerde çokkültürlülük tanımları, yaptıkları 
etkinlikler, aile katılımı algıları ve çokkültürlü ailelere yönelik yapılan etkinlikler çerçevesinde 10 farklı soru sorularak veri toplama süreci tamamlanmıştır.

Tablo 3. Yarı Yapılandırılmış Görüşme Formu Soruları

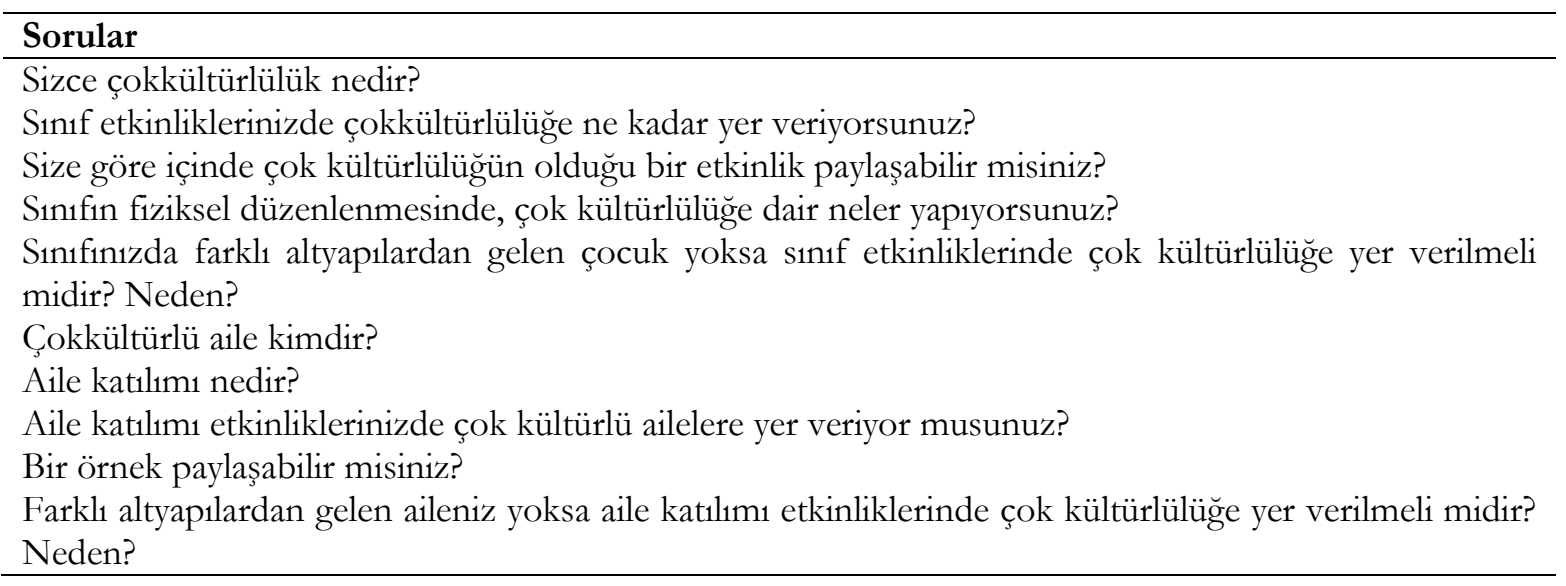

\section{Verilerin Analizi}

Toplanan veriler içerik analizi tekniği ile analiz edilmiştir. İçerik analizinin temel amacı, birbiri ile ilişkili olan verileri belirli temalar altında organize ederek bir araya getirmek ve yorumlamaktır (Yıldırım ve Şimşek, 2008). Verilerin geçerliğini sağlanması için Creswell (2013) tarafından önerilen aşağıdaki adımlar iki farklı kodlayıcı tarafından izlenmiştir:

İlk adım olarak veriler, analize uygun hale getirmek amacıyla hazırlanmıştır ve bilgisayar ortamına aktarılarak düzenlenmiştir. Katılımcılar numaralandırıldıktan sonra içeriğe dair derinlemesine düşünme yapmak amacıyla verilerin tamamı okunmuş ve incelenmiştir. Üçüncü basamakta veriler bağımsız iki kodlayıcı tarafindan incelenmiş ve kodlanmıştır. Bu süreçte sadece katılımcılardan elde edilen verilere dayanarak kodlar geliştirilmiş ve kodlar tablosu oluşturulmuştur. Tabloda, her kodun etiketi ve koda ilişkin görüşme formlarından elde edilen bilgilere yer verilmiştir. Elde edilen iki farklı kodlar tablosu, görüş birliğinin sağlanması amacıyla karşılaştırılmış ve tekrar incelenerek erken çocukluk dönemi öğretmenlerinin çok kültürlülük uygulamalarına ilişkin temalar belirlenmiştir. Verilerin geçerliğini desteklemek amacıyla her temanın altında, temaya nasıl ulaşıldığını açıklayan doğrudan alıntılara yer verilmiştir (Creswell, 2013).

\section{BULGULAR}

Erken çocukluk dönemi öğretmenlerinin çokkültürlülük uygulamaları hakkında bilgi edinmek için araştırmacılar tarafindan oluşturulan görüşme formu aracılı̆ğ ile toplanan veriler içerik analizi yöntemi ile incelenmiş, incelemeler doğrultusunda "Çokkültürlülük Tanımları", "Çokkültürlü Aile 
Anlayışları”, “İletişim Yöntemleri”, “Çokkültürlü Etkinlikler” ve “Aile Katılım Tanımları” olmak üzere beş ana tema belirlenmiştir.

\section{Çokkültürlülük Tanımları}

Erken çocukluk dönemi öğretmenlerinin çokkültürlülüğe dair tanımları incelendiğinde, yaptıkları tanımların ırk, dil, din ve sosyoekonomik durum çeşitliliği gibi kavramlar etrafında şekillendiği belirlenmiştir.

\footnotetext{
"Yani farklı dinlerden, ırklardan bir araya gelen çocuk, çocuklar geliyor benim aklıma. Çok kültürlülük birden fazla ülkenin hani... O ülkeye ait giyim, kuşam, dil, kültür olarak hepsinin bir arada yansitilmasidır” (Ö1)

"Yani bana göre birçok din ayrımı, mezhep ayrımı." (Ö2)

“Farklı altyapıdan ailelere sosyoekonomik durumu düşük aileler girer.” (Ö3)
}

Öğretmenlerin çokkültürlülüğü, kavram ile ilgili olan "kültür” kelimesinin yardımı ile tanımladığ1 belirlenmiştir. $\mathrm{Bu}$ noktada öğretmenler çokkültürlülüğü uygulamadan bağımsız olarak ifade etmemiş ve tanımlarını oluştururken yaptıkları etkinlik örneklerinden faydalanmışlardır.

"Farklı kültürlerden gelen insanların bir arada yaşamaya çalışmasıdır, sosyal ortamlarda, okullarda, dişarda, diş çevrede." (Ö3)

"Yani çokkültürlülük dendiği zaman benim aklıma bir bireyin farklı kültürler olarak yetişmesi, etnik bir kendi kültürünü oluşturulması geliyor aklıma.” (Ö7)

“Çokkültürlülüğe dair tanımım yok (...) Örnek veriyorum, 23 Nisan geliyor, 19 Mayıs geliyor, o zaman özel günlerde (çokkültürlülüğü) anlatmaya çalışıyoruz." (Ö4)

\section{İletişim Yöntemleri}

Erken çocukluk dönemi öğretmenlerinin çokkültürlü aileler ile kurdukları iletişimin beden dili (sözsüz iletişim), resmi olmayan tercüman desteği, başka bir aile desteği veya çocuklar aracıllğı ile sağlandığı ifade edilmiştir. 


\section{Aile Katılımı Tanımları}

Katılımcılar için aile katılımı, genel olarak okul ve ailelerin işbirliği içerisinde çocuk için çalışması olarak tanımlanmıştır.

“Aile katılımı, okul ve aile iş birliği içerisinde çocuğun eğitimleri için... Yani eğitime ailenin de katılması." (Ö3)

"Eğitimde çocukların aile ile beraber devam etmemiz gerekiyor. Okulda sonuçta tek başına yeterli olmuyor. Aile katılımı çocukların eğitimi olarak aklıma geliyor. Aile katılımı çocukların etkinliklerinde, gerek okul yaşantısına, gerek diğer yaşantılarına ailenin bizzat öğretmen ve okulla iletişimde olarak bu süreci beraber yönlendirmesi geliyor." (Ö7)

Aile katılımı ile ilgili diğer bir bakış açısı ise öğretmenlerin katılımı "ailenin çocuğuyla vakit geçirmesi için kullanılan bir yol, bir etkinlik" olarak değerlendirmiş olmasıdır.

“Ailenin çocuklarla beraber yaptı̆̆ herhangi bir şey. Herhangi bir etkinlik.”(Ö5)

“Aile katılımı çocukla beraber, yani çocuk olarak düşünüyorum, çocukla beraber bir şeyler yapabilmek, paylaşabilmek, konuşabilmek, aile katılımı ile çocuğun özgürlüğüne, her şeyine destek olabilme” (Ö6)

"Bizde daha çok aile ile vakit geçirmesi peşindeyiz. Aile ile kaliteli vakit geçirmesi için daha çok aile katılımı veriyoruz.” (Ö3)

Katılımcıların aile katılımı tanımları incelendiğinde, kavramı temelde ev temelli ve okul temelli olarak tanımladıkları ve okul ve ev olarak iki ayrı alanda değerlendirdikleri bulgusuna ulaşılmıştır.

"Evde olabilir, burada olabilir, bazen aile katılımı okullarda oluyor. Biz de mesela bazen velilerimizi, mesela bizim sürpriz günümüz var. Çocuklar aileleriyle beraber bir şey hazırlayıp, yiyecek olarak hazırlayıp getiriyorlar mesela." (Ö6)

\section{Çokkültürlü Aile Anlayışları}

Erken çocukluk dönemi öğretmenlerinin çokkültürlü aileleri tanımlamaları istenmiş ve elde edilen bulgulara göre bu konuda farklı anlayışlarının olduğu tespit edilmiştir. Bir grup erken çocukluk dönemi öğretmeni ise çokkültürlü aileyi farklı din, dil, ırk gibi olgulara sahip aile olarak tanımlarken, diğer öğretmenler çokkültürlü aileyi çok okuyan ve çok gezen aile olarak tanımlamışlardır.

"Mesela atıyorum annesinin Arap olup babasının Türk ya da daha farklı bölgelere ait hem şive hem yaşayış olarak farklı”(Ö1) 
“Aile büyüklerinin farklı kökenlerden oluşmuş aile aklıma geliyor” (Ö6)

"Yalnızca değişik kültürlerden insanlar" (Ö4)

"Çokkültürlü aile... Çok okumuş aile değildir bence. Kendini sınırlamayan, her yeri tanımak amacıyla gezen aile çokkültürlü ailedir bence.” (Ö3)

“Çok gezen değil midir? Çok gezen yani bana göre.” (Ö2)

"Çokkültürlü aile, iyi bir eğitim almıştır, çocuğuna iyi bir gelecek hazırlamıştır, kültürünü de geliştirmiştir.’(Ö6)

\section{Çokkültürlü Etkinlikler}

Görüşmeler sırasında katılımcılardan sınıf içi ve aile katılım etkinliklerinde uyguladıkları çokkültürlülük ile ilişkili bir etkinlik örneği anlatmaları istenmiştir. Elde edilen veriler incelendiğinde, katılımcılardan bazılarının sınıf içi etkinliklerinde daha çok şehirler ve ülkeler arası yiyecek ve giyecek farklılıklarına vurgu yaptıkları bulunmuştur. “Evet, her ay belli bir bölge seçilip o bölge çocuklarla veya aileleriyle beraber öğrenildi. Kimisi yiyecek
getirdi, kimisi bir poster hazırladı. Mesela o da kendi Bölgesi'ne ait değişik bir tatlı yapmıştı, annesi onu
getirmişti”(Ö1)

"Ben Kazakistanlı olan ailenin Kazakistanlı olan çocuğun ailesinden kendi kültürlerini tanıtmaları istemiştim. Ben farklı bir kültür olduğu için gelip işte Kazaklara özgü kıyafetleri, yiyecekleri varsa onları göstermesini, resimleri göstermesini istemiştim. Bu tür farklı bir etkinlik yapmıştık.” (Ö7)

"Biz aile katılımında özellikle kim nereli ise kendi memleketini anlatsın istiyoruz.” (Ö2)

Çalışmada yer alan diğer erken çocukluk dönemi öğretmenlerinin ise sınıf içi etkinliklerinde çokkültürlülük konusunu belirli gün ve haftalarda yapılan etkinlikler çerçevesinde ele aldıkları tespit edilmiştir.

“İşte dediğim gibi çokkültürlü etkinliklere belirli gün ve haftaların izin verdiği derecede yer veririm.”(Ö4)

“Yani konuya göre değişiyor çünkü Millî Eğitim Bakanlığı’na bağlı bir kurum olduğu için sürekli belirli bir müfredatımız var. Ona göre yer vermeye çalısııoruz. Yani genelde 23 Nisan'da falan da çok oluyor."(Ö6)

Katılımcıların uyguladıkları aile katılım etkinlikleri incelendiğinde, ailelerle birlikte şehir/ülke tanıtım etkinlikleri düzenledikleri sonucuna ulaşılmışır. 
"Ailesi sunum anlatıyor. Aile ve çocuk beraber yapıyor. İşte mesela kendi kıyafetleri oluyor bir bölümde, kendi yiyecekleri, kendi konuşma dilleri, kendi ülkelerine ait resimler, kendi annesi babası kardeşleri hem ailesini hem kendi ülkesini tanıtıyor.” (Ö6)

\section{SONUÇ ve TARTIŞMA}

En genel anlamıyla çokkültürlülük aynı sosyal ortamda bulunan ve farklı gelenekleri, dilleri, dinleri ve alışkanlıkları olan bireylerin hem bu farklılıkları korumaya çalışması hem de bu farklılıkların toplum tarafindan tanınmasını ifade eden bir kavram olarak tanımlanır (Colombo, 2014). Mevcut çalışma, okul öncesi eğitim kurumlarında görev yapmakta olan öğretmenlerin çokkültürlülük anlayışlarını incelemek amacıyla yapılmıştır. Bu bağlamda sınıfta uyguladıkları çokkültürlülük etkinlikleri ve çokkültürlü aileler ile yaptıkları aile katılım çalışmaları hakkında bilgi edinmek amaciyla 10 sorudan oluşan bir görüşme formu oluşturulmuş ve öğretmenlere uygulanmıştır. Yapılan içerik analizi sonucunda "Çokkültürlülük Tanımları”, "İletişim Yöntemleri”, “Aile Katılım Tanımları", "Çokkültürlü Aile Anlayışları", ve "Çokkültürlü Etkinlikler” olmak üzere beş ana tema belirlenmiştir.

Hem jeopolitik konumu hem de teknolojik ve ekonomik değişimler gibi sebeplerden ötürü Türkiye çokkültürlü ülkelerden biri haline gelmiştir (Aydın, 2012). Bu süreçte çokkültürlülük toplumun her alanında bireylerin karşısına çıkan olgulardan biridir. Özellikle eğitim, toplumun farklı kültürel yapısını hem etkileyen hem de bu farklı yapılan etkilenen başlıca alanlardan biridir. Bu sebeple öğretmenlerin sahip olduğu çokkültürlülük alg1sı farklılıklar içinde herkes için adil eğitim fırsatları sağlamak açısından önemlidir (Banks, 2002). Katılımcıların çokkültürlülük tanımları incelendiğinde bazı öğretmenlerin çokkültürlülüğü $1 \mathrm{rk}$, dil din ve sosyoekonomik durum çerçevesinde ele aldığ1 bulunmuştur. Halbuki aile yapısı, cinsel yönelim ve yaş da çokkültürlülüğe yol açan ana etmenler olarak kabul edilmektedir (Berger, 2004; Polat ve Kilıç, 2013). Bu durum öğretmenlerin çokkültürlülüğü oluşturan unsurlar hakkında sınırlı bilgiye sahip olduğu anlamında yorumlanabilir. Mevcut çalışmanın bulgularıyla paralel olarak Berthelsen ve Karuppiah (2011) tarafindan yapılan bir çalışmada, öğretmenlerin çokkültürlülük anlayışlarının sınırlı olduğu tespit edilmiştir. Çokkültürlü ülkelerden biri olan ve farklı dilleri bir arada bulunduran Singapur'da gerçekleştirilen bu çalısmada öğretmenler çokkültürlülüğü ırk ve etnik köken kapsamında değerlendirmiştir (Berthelsen ve Karuppiah, 2011). Mevcut çalışmaya katılan diğer öğretmenlerin çokkültürlülüğe dair bir tanımları olmamasına rağmen sınıf içi uygulamalarında çokkültürlülüğe ilişkin etkinlikler yapmaları ise umut verici olarak değerlendirilebilir. İkinci olarak katıllmcıların çokkültürlülüğü tanımlarken, tanım cümlesi kurmaktan çok sınıf içi deneyimlerinden örnekler vererek açıladıkları 
belirlenmiştir. Bu açıklama yöntemi yazarın; öğretmenlerin çok kültürlülüğü öğrenme sisteminin bir parçası, bir öğrenme deneyimi olarak değerlendiriyor olmaları varsayımına ulaşmasına neden olmuştur.

Mevcut çalışmada öğretmenlerin sahip oldukları farklı çokkültürlülük tanımlarının aileler ile olan iletişimleri ile bir bağlantı içinde olabileceği tespit edilmiştir. Erken çocukluk döneminde ailelerle yakın ilişki karşılıklı güven ve saygı üzerine kurulmaktadır. Bronfenbrenner'in Ekolojik Sistemler Teorisi düşünüldüğünde, öğretmen ile ailenin açık iletişim kurması mikrosistemler arası ilişkiyi ve dolayısıyla mesosistemi güçlendiren önemli bir faktördür. Fakat çokkültürlü yapılardan gelen aileler ile çalışırken bu ilişkinin kurulması öğretmenler açısından zor olabilmektedir (Eberly ve diğerleri, 2017). Mevcut çalışmada öğretmenler çokkültürlülüğü dil, din ve etnik köken gibi kavramlar etrafinda tanımlarken iletişim yöntemlerinde sadece dil ve onunla ilgili deneyim ve engellerden bahsetmektedirler. Bu durum öğretmenlerin çokkültürlülük ile ilgili birincil alg1larının farklı dilde konuşan aileler olduğu olarak yorumlanabilir. İlgili alanyazın tarandığında, aile katıllım sürecinde karşılaşılan dil bariyerinin birçok çalışmada odak noktası olduğu görülmektedir (Chu ve Garcia, 2014; Hughes ve MacNaughton, 2000; Rios ve Wynn, 2017). İsveç'te yürütülen bir çalışmada, öğretmenler çokkültürlü ailelerle çalışırken en zorlandıkları konunun dil ve iletişim problemleri olduğunu belirtmiştir (Hughes ve MacNaughton, 2000). Benzer şekilde Amerika'da yürütülen bir çalışmada ise çokkültürlü ailelerin öğretmenlerle iletişimlerinin diğer ailelere kıyasla daha kısa sürdüğ̈̈ tespit edilmiştir (Rios ve Wynn, 2017). Kısa süren bu iletişim sürecinin ise öğretmenin sözel olmayan iletişim yöntemleri ve bazı iletişimsel uyarlamalar yapması ile şekillendiği ifade edilmiştir. Bu bulgular, öğretmenlerin iletişim sürecinde beden dili gibi geçmişten getirdikleri donanımları kullandığını ortaya çıkaran mevcut çalışmanın bulguları ile paraleldir. Ebeveynler açısından ele alındığında çokkültürlü aileler, okul takvimlerini ve eve gönderilen notları okumakta zorluk yaşadıklarını ifade etmektedir (Chu ve Garcia, 2014). Okulda yürütülen aile katılımı çalışmalarının okul-ev iletişiminin ne kadar etkin olduğuna bağlı olduğu düşünüldüğünde (Vassallo, 2018), çokkültürlü ailelerle kurulan iletişim sürecinin iki yönlü ve açık olması kritik bir rol oynamaktadir.

Öğretmenlerin, çokkültürlü ailelerle yaptıkları aile katılım etkinliklerini paylaşmalarından önce aile katılımını tanımlamaları istenmiştir. Elde edilen bulgular, öğretmenlerin aile katılımı sürecini ev temelli ve okul temelli olarak ayrı ayrı değerlendirdiğini göstermektedir. Ek olarak bazı öğretmenler aile katılımını okul ve aile arasında kurulan işbirliği çerçevesinde tanımlamaktadır. Bu durumun ilgili alanyazındaki aile katılımı tanımlamaları ile örtüşmesine rağmen (Demircan, 2018; Hornby, 2011), çokkültürlü aileler ile iletişimde tercih edilen yöntemleri işbirliğinin kurulması için yeterli değildir. 
Pepito (2019) tarafından yapılan bir çalışmada öğretmenlerin ortaklık pratiği olarak açı iletişim kanallarını tercih ettiği ifade edilmiştir. Bu sebeple güçlü bir işbirliği ve ortaklık için iletişimin yazılı metinleri tercüme etme seviyesinde kalmamas1 gerekmektedir (Bower ve Griffin, 2011). Epstein (1992) oluşturduğu aile katılımı modelinde iletişimin aile katılım yöntemlerinden biri olduğunu ifade etmektedir. Epstein'in iletişim pratikleri incelendiğinde tercüman desteği sağlama ve çoğunluktan farklı dili konuşan aileleri de sürece dahil ederek çift yönlü iletişim kanalının oluşturulması gerekliliği ortaya çıkmaktadır. Ek olarak öğretmenler aileler ile işbirliği süreçlerinde resmi olmayan tercüman desteği aldıklarını ifade etmiştir. Bu durum öğretmenlerin çokkültürlülük çalışmaları süresince toplum destekli yol aldıkları anlamına gelebilir. Diğer yandan öğretmenlerin aile katılımı konusunda ailelere aktif roller yüklemesi eğitim programları ve çocuk gelişimi açısından olumlu yönde değerlendirilmelidir. Çünkü alan yazında öğretmenin aile katılımı konusunda yeterli bilgiye sahip olmadığını ve öğretmenin olumsuz algılarının aile katılımı sürecinde bir bariyer olduğunu ortaya koyan araştırmalar bulunmaktadır (Johnson, 2011).

Mevcut çalışmada aile katılımına dair tanımlama yapan öğretmenlerden ayrıca çokkültürlü aileleri tanımlamaları istenmiştir. Elde edilen bulgular, çokkültürlü aileler konusunda bazı öğretmenlerin kavram yanılgısı yaşayabildiğini ortaya koymaktadır. Çalışmada yer alan bazı öğretmenler, çokkültürlü aileyi çok gezen, çok okuyan aileler olarak tanımlamıştır. Alanyazın incelendiğinde en genel tanımıyla çokkültürlü aileler, farklı milletlerden gelen aileler olarak tanımlanmaktadır (Chang, Hsu, Shih \& Chen, 2014). Çalışmaya katılan diğer öğretmenler ise çokkültürlü aileyi farklı kökenlerden oluşan, farklı kültürleri içeren aile olarak ifade etmiştir. Öğretmenlerin çokkültürlülüğü oluşturan unsurlar hakkında bilgi sahibi olması, çokkültürlü ailelerin okula getirdiği kültürel kaynaklardan faydalanmaları ve bu kaynakları sınıf içi uygulamalarında kullanmaları açısından gerekli görülmektedir (Vassallo, 2018). Mevcut çalışmanın bulguları, öğretmenlerin çokkültürlü aileler ile ilgili bilgi sahibi oldukları yönünde değerlendirilebilir.

Son olarak öğretmenlerin uyguladığı çokkültürlü etkinlikler ele alındığında, katılımcıların hem sınıf içi hem de aile katılımı sürecinde çokkültürlülüğe ilişkin uygulamalar yaptığı bulunmuştur. Milli Eğitim Bakanlığ1 2013 Okul Öncesi Eğitim Programı çokkültürlülük açısından incelendiğinde, programda Kazanım 8. Farklılıklara sayg1 gösterir" ve "Kazanım 9. Farklı kültürel özellikleri açıklar.” kazanımları yer almaktadır. Bu kazanımlar doğrultusunda öğretmenin sorumluluklarından biri çocukların bireysel, sosyal ve kültürel farklılıkları zenginlik olarak değerlendirip saygılı tutum göstermesi için uygun etkinlikler düzenlemektir (Milli Eğitim Bakanlığ1, 2013). Çocukların kendi ülkesinin kültürünü tanıması ve daha sonra farklı kültürleri tanıtacak deneyimler kazanması çokkültürlülük kazanımları çerçevesinde değerlendirilmekte, farklılıklar kadar ülkelerin sahip 
oldukları ortak değerlerin de vurgulanması beklenmektedir (MEB, 2013). Mevcut çalışmada sınıf içi etkinlikler incelendiğinde, bazı öğretmenlerin çokkültürlü ailelerin kendi kültürlerine ve geldikleri şehir/ülkeleri anlatan "gönüllülük esaslı" etkinliklerine odaklandıkları ortaya çıkmıştır. Bu etkinliklerin genel anlamda yiyecek ve giyecek ile ilgili farklılıklara odaklandığ1 bulunmuştur. $\mathrm{Bu}$ durum öğretmenlerin çokkültürlülüğü eğitim ortamında değerlendirdiği ve yaş grubunun gelişimsel özelliklerini değerlendirerek somut örnekler ile ele aldığı anlayışı çerçevesinde yorumlanabilir. Alanyazın incelendiğinde erken çocukluk döneminde yapılan çokkültürlü çalışmaların somut örnekler olan yiyecek ve giyecek gibi kavramlar üzerine odaklandığı gösteren başka çalışmalar da mevcuttur (Erse-Alves, 2016; Tarman ve Tarman, 2011). Mevcut çalışmayla paralel olan ve çokkültürlülüğe dair somut örnekler sunan bu çalışmalar gelişimsel olarak uygun öğrenme ortamına ulaşmak adına değerlidir. Ek olarak çokkültürlü ailelerin okul ile işbirliğine az katıldıkları göz önüne alındığında (Artiles, Kozleski, Trent, \& Ortiz, 2010; Fishman ve Nickerson, 2015), öğretmenlerin çokkültürlü ailelere yönelik aile katılımı etkinlikleri planlaması çokkültürlü ailelerin eğitime katılım sürecini teşvik eden ve artıran bir durum olarak değerlendirilmelidir.

Çalışma bulguları değerlendirildiğinde, okul öncesi öğretmenlerinin çokkültürlülük tanımlamalarında benzer ve farklı yönlerin olduğu ifade edilebilir. Ek olarak, sınıf içi uygulamalarında ve aile katılımı etkinliklerinde de şehir/ülke tanıtımlarına odaklanarak benzer süreçlerden geçtikleri söylenebilir. Okul öncesi öğretmenlerinin sahip oldukları farklı çokkültürlülük alg1ları, çokkültürlülüğe dair etkinlikler uygulamalarına destek olmaktadır. Öte yandan çokkültürlülük kavramı çağımızda hızla değişen kültürel ve sosyal sistemler içerisinde güncelliğini korumakta, eğitim sistemi içinde güncel ve bilimsel bir altyapı çerçevesinde yerini almaktadır. Bu nedenle araştırma bulguları 1şığında; okul öncesi öğretmenlerinin, öğretmen eğitim programları aracılığı ile veya hizmetiçi eğitimler ile güncel, çağın ihtiyaçlarını gözeten bilgilere ulaşması önemini korumaktadır. 


\section{KAYNAKÇA}

Artiles, A., Kozleski, E. B., Trent, S. Osher, D., \& Ortiz, A. (2010). Justifying and explaining disproportionality, 1968-2008: A critique of underlying views of culture. Exceptional Children, 76, 279-299.

Aydın, H. (2012). Multicultural education curriculum development in Turkey. Mediterranean Journal of Social Sciences, 3(3), 277-286.

Banks, J. A. (2002). An Introduction to Multicultural Education. Boston, MA: Ally \&Bacon.

Barnett, W.S., Yarosz, D.J., Thomas, J., Jung, K., \& Blanco, D. (2007). Two-way and monolingual English immersion in preschool education: An experimental comparison. Early Childhood Research Quarterly, 22, 277-293.

Berger, E. H. (2004). Parents as partners in education: Families and schools working together. New Jersey, NJ: Pearson.

Berthelsen, D. \& Karuppiah, N. (2011). Multicultural education: The understandings of preschool teachers in Singapore. Australasian Journal of Early Childhood, 36 (4), 38-42.

Bower, H.A., \& Griffin, D. (2005). Can the Epstein model of parental involvement work in a high-minority, high-poverty elementary school? A case study. Professional school Counseling, 15(2), 77-87.

Chang, J.H., Hsu, C.C., Shih, N.H., \& Chen, H.C. (2014). Multicultural families and creative children. Journal of Cross - Cultural Psychology, 45(8), 1288 - 1296.

Chu, S., \& García, S. B. (2014). Culturally responsive teaching efficacy beliefs of special special education teachers. Remedial and Special Education, 35,218-232.

Colombo, E. (2014). Multiculturalisms. Sociopedia, 1-17. https://doi.org/10.1177/2056846014101

Creswell, J. W. (2013). Research design: Qualitative, Quantitative, And Mixed Methods Approaches. Thousand Oaks, CA: Sage Publications.

Demircan, H. Ö. (2018). Okul öncesi eğitimde sistemi genişletmek: Aile-ebeveyn "bağllliğ1, işbirliği, katılımı ve eğitimi”. İlköğretim Online, 17(4), 1-19. 
Derman-Sparks, L., \& Olsen Edwards, J. (2010). Anti-bias Education for young children and ourselves. Washington, DC: NAEYC

Eberly, J., Joshi, A., \& Konzal, J. (2007). Communicating with families across cultures: an investigation of teacher perceptions and practices. School Community Journal, 17(2), 7-26.

Erse-Alves, I. M. (2016). Teaching multiculturalism in a preschool classroom. (Yayınlanmamış yükseklisans tezi). Lizbon Eğitim ve Bilim Enstitüsü, Portekiz.

Epstein, J.L. (1992). School and family partnerships. In M. Alkin (Ed.), Encyclopedia of educational research (pp. 1139-1512). New York: MacMillan

Fishman, C. E., \& Nickerson, A. B. (2015). Motivations for involvement: A preliminary investigation of parents of students with disabilities. Journal of Child and Family Studies, 24, 523-535.

Hong, Y. (2017). Facing diversity in early childhood education: teachers' perceptions, beliefs, and teaching practices of anti-bias education in Korea. MSU Graduate Theses. 3188. https://bearworks.missouristate.edu/theses/3188

Hornby, G. (2011). Parental Involvement In Childhood Education: Building Effective School-Family Partnerships. New York: Springer.

Hughes, P., \& McNaughton, G. (2000). Consensus, dissensus or community: the politics of parent involvement in early childhood education. Contemporary Issues in Early Childhood, 1(3).

Johnson, F. V. (2011). Examining the impact of teacher perceptions of barriers of parental involvement. ProQuest LLC. 789 Retrieved from http://www.proquest.com/en-US/products/dissertations/individuals.shtml.

Keat, J.B., Strickland, M.J., \& Marinak, B.A. (2009). Child voice: How immigrant children enlightened their teachers with a camera. Early Childhood Education Journal, 37(13), 13-21.

Keyes, C. R. (2002). A way of thinking about parent/teacher partnership for teachers. International Journal of Early Years Education, 10, 177.191.

Kurtuluş, F. (2018). Çokkültürlü bazı ülkelerde eğitim politikaları ve öğretmen eğitimi. Anadolu Üniversitesi Eğitim Fakültesi Dergisi, 2(3), 178-195.

Ladky, M., \& Stagg-Peterson, S. (2008). Successful practices for immigrant parent involvement: An Ontario perspective. Multicultural Perspectives, 10(2), 82-89. 
Lahaie, C. (2008). School readiness of children of immigrants: Does parental involvement play a role? Social Science Quarterly, 89(3), 684-705.

Lareau, A. (1987). Social class differences in family-school relationships: the importance of cultural capital. Sociology of Education, 60, 70-74.

Lin, Q. (2005). Multicultural visions in early reading classrooms: Implications for early childhood teacher educators. Journal of Early Childhood Teacher Education, 25(3), 237-245.

Lynch, E. \& Hanson, M. (Eds.) (1998). Developing Cross-Cultural Competence: A Guide For Working with Children And Their Families (2. Baskı). Baltimore: Paul H. Brookes.

MEB (2013). Okul öncesi eğitim programı. Web:http://tegm.meb.gov.tr/www/okulöncesiegitimprogrami-ve-kurul karari/içerik/54 3 Kasım 2019'da alınmıştır.

Mendible, M. (1999). What is multiculturalism. St.James Encyclopedia of Popular Culture.

Moawad, N. \& Shoura, S. (2017). Toward a richer definition of multiculturalism. International Journal of Advanced Research, 5(7), $802-806$.

ÖzÖzen, M., Eran, N., Nuray, D., Çetin, Z., Pınarcık, Ö, Bahtiyar, M. (2016). Okul öncesi öğretmenlerinin çok kültürlü eğitime yönelik tutumları. Eğitim Arastırmalar Dergisi, 2(1), 73 86.

Polat, İ. \& Kllıç, E. (2013). Multicultural education in Turkey and teachers' competencies in multicultural education. Yüəüncü Yal Üniversitesi Ë̆itim Fakültesi Dergisi, 10(1), 321-351.

Pepito, G. (2019). Home-school partnership in kindergarten. Indernational Journal for Innovative Research in Multidisciplinary Field, 5(6), 171-175.

Rattansi A (2011) Multiculturalism: A Very Short Introduction. Oxford: Oxford University Press.

Rios, K., \& Wynn, A. N. (2017). Engaging with diversity: Framing multiculturalism as a learning opportunity reduces prejudice among high White American identifiers. European Journal of Social Psychology, 48(55).

Schölmerich, A. , Leyendecker, B., Citlak, B., Caspar, U. \&amp; Jakel, J. (2008). Assessment of migrant and minority children. Journal of Psychology, 216(3), 187-194. Doi:10.1027/oo443409.216.3.187.

Swick, K.J., Boutte, G., \& Scoy, I. (1994). Multicultural learning through family involvement. Dimensions, 22(4), 17-21.

Tarman, İ., \& Tarman, B. (2011). Developing effective multicultural practices: A case study of 
exploring a teachers' understanding and practices. Uluslararası Sosyal Araştrrmalar Dergisi, 4(17), 578-598.

Taştekin, E., Bozkurt Yükçü, Ş., İzoğlu, A., Güngör, İ., Işık Uslu , A. E., ve Demircioğlu, H. (2016). Okul öncesi öğretmenlerinin çokkültürlü eğitime yönelik tutumlarının ve alg1larının incelenmesi. Journal of Educational Research, 2(1), 1-20.

Tiedt, P. L., Tiedt, I. M. (2005). Multicultural Teaching: A Handbook of Activities, Information and Resources (2.Baskı). Boston, MA: Pearson Education, Inc.

Turner - Vorbeck, T. A. (2005). Expanding multicultural education to include family diversity. Understanding Family Diversity, 6-10.

Turney, K., \& Kao, G. (2009). Barriers to school involvement: Are immigrant parents disadvantages? The Journal of Educational Research, 102(4), 257-271.

Turkey Directorate General of Migration Management (2020, May 03). Residence permits. https://en.goc.gov.tr/residence-permits

Vassallo, B. (2018). Promoting parental involvement in multicultural schools: implications for educators. The Online Journal of New Horizons in Education, 8(2), 101-107.

Vellymalay, S. K. N. (2012). Parental involvement at home: Analysing the influence of parent's socio-economic status. Studies in Sociology of Science, 3(1), 1-6.

Vittrup, B. (2016). Early childhood teachers' approaches to multicultural education \& perceived barriers to disseminating anti-bias messages. Multicultural Education, 23, 37-41.

Yanık-Özger, B., \& Akansel, A. (2019). Okul öncesi sınıfındaki suriyeli çocuklar ve aileleri üzerine bir etnografik durum çalışması: Bu sınıfta biz de varı! Egitimde Nitel Araşstırmalar Dergisi, 7(3), 942-966. doi: 10.14689/issn.2148-624.1.7c.3s.3m

Yıldırım, A. \& Şimşek, H. (2008). Nitel Araştırma Yöntemleri. Ankara: Seçkin Yayıncılık. York, S. (2016). Roots And Wings: Affirming Culture And Preventing Bias in Early Childhood (3.bask1). Minnesota: Redleaf Press. 